\title{
Quantifying Poverty Temporal Changes in Association with Rural Transition in Guangxi, China
}

\author{
Heyuan You \\ School of Public Administration, Zhejiang University of Finance and Economics, Hangzhou 310000, China \\ Correspondence should be addressed to Heyuan You; youheyuan@gmail.com
}

Received 4 June 2016; Accepted 8 August 2016

Academic Editor: Jean-Pierre Corriou

Copyright (C) 2016 Heyuan You. This is an open access article distributed under the Creative Commons Attribution License, which permits unrestricted use, distribution, and reproduction in any medium, provided the original work is properly cited.

\begin{abstract}
Poverty is a social problem in developing countries, especially for the rural places experiencing rapid transition. This study characterizes the temporal changes of rural poverty under rural transition during 1991-2010 in Guangxi. In particular, poverty is measured by the Foster-Greer-Thorbecke method, and rural transition is described from three aspects including rural industrialization, regional urbanization, and agriculture commercialization. Relationships are quantified by multivariate linear regression. Results reveal that industry income proportion (IIP) and secondary industry proportion (SIP) are positive contributors to the poverty incidence, while urban-rural income gap (URIG) is a negative contributor to the poverty incidence. Industrial total output of township and village enterprises (ITOE), IIP, and grain commercialization rate (GCR) present positive correlation with the poverty depth. The URIG has a negative correlation with the poverty depth. Tertiary industry proportion (TIP) and expenditure on fixed productive assets per capita (EFPA) are positively correlated with the poverty severity, while URIG and power of agricultural machinery (PAM) associate with poverty severity negatively. Redundancy analysis shows that individual influence of rural industrialization is higher than that of regional urbanization and agriculture commercialization. The joint influences of rural industrialization, regional urbanization, and agriculture commercialization are the strongest.
\end{abstract}

\section{Introduction}

Poverty alleviation is a primary goal of rural development in China [1], and China's Central Government has initiated several antipoverty programs during the last three decades [2]. The rural household income associated with the rapid economic growth in China has increased rapidly [3], and the population living in poverty has been decreased drastically in rural China [4]. But the researches using internationally comparable poverty lines, rather than the Chinese official poverty line which is relatively low, indicate that the rural poverty in China is still a serious problem, especially in the southwestern regions [5,6]. And the government still faces many challenges to alleviate residual poverty. Indeed, the poverty headcount ratio in China was still $11.2 \%$ in 2010 at a $\$ 1.90$ a day [7]. At the end of 2014, China still had 70.17 million people in rural areas living below the official poverty line of $2300 \mathrm{RMB}$ in annual income using 2010 constant price [8]. Meanwhile, places and individuals benefit from China's rapid economic growth unequally [9]. The inequality between lowincome rural household and high-income rural household as well as that between rural places and urban cities slacks the rural poverty alleviation. It decreases the elasticity of rural poverty reduction due to rural economic growth [10].

Poverty dynamics analysis has achieved a large advancement in recent years. Yu revealed that rapid economic growth has resulted not only in a decrease in income poverty but also in a decrease in multidimensional poverty in the last decade using China Health and Nutrition Survey 2000-2009 data [4]. Ferreira et al. found that one important reason for slow pace of poverty reduction between the mid-1980s and the mid-2000s in Brazil is that economic growth plays a relatively small role in poverty reduction [11]. Some methods for assessing poverty dynamics have been put forward [12]. Cheli and Betti provided a fuzzy analysis for assessing poverty dynamics on an Italian pseudo-panel 1985-1994 [13]. Verma et al. also presented a fuzzy measurement for analyzing longitudinal aspects of monetary and multidimensional poverty [14]. 
Duclos et al. selected JR's approach to separate poverty into chronic and transient components and measured chronic and transient poverty in China using a rich panel data set [15]. Hulme and Shepherd conceptualized the chronic poverty in a nutshell and analyzed chronic poverty dynamics [16]. Hoy and Zheng provided an axiomatic framework for measuring lifetime poverty over multiple periods [17]. Gradín et al. presented an intertemporal poverty index which is consistent with the meaning of longitudinal poverty [18].

Research indicates that many factors influence the temporal changes of rural poverty. Economic growth is considered as the most important factor for alleviating rural poverty. However, the role of economy can be insignificant [11], given the inequity in income distribution [19]. Geography also has a close relationship with rural poverty. Carter and Barrett evidence the existence of geographic poverty traps using an asset-based approach [20]. The geographic poverty traps in rural areas are primarily associated with the high transportation costs, less-favored agricultural land, and poor public investment [21, 22]. Individual and household characteristics are also correlated with rural poverty. Human capital investment, such as education and health, is related to the farmer endowments for income [23]. Recent studies have highlighted that family structure and land distribution can impact the poverty incidence and poverty alleviation in rural areas $[24,25]$. Rural transition in China reflects the then-current ideas about strategy and policy of government for rural development [26]. The rural industrialization, regional urbanization, and agricultural commercialization are described as three important aspects of rural transition in China. It increases the farmers' income and grain yield, eliminates the rural poverty, transfers the rural labor to the nonagricultural industries in urban areas, and stimulates the migration of farmers to settle permanently in cities or towns [27-31]. The rural transition plays a key role in the poverty alleviation in the early stage of open-door reform; however, the effect of rural transition on rural poverty is dubious considering the serious imbalance development of rural and urban areas in China. Meanwhile, the joint influences of rural industrialization, regional urbanization, and agricultural commercialization have close interactions between each other. In this context, it is a worthwhile attempt to analyze the poverty temporal changes in association with the three components of rural transition.

Several measures of poverty are proposed in previous literature. The headcount ratio which is a single poverty indicator selected in the early poverty measure is the proportion of a population that is classified as poor. It usually is defined as the population living below the poverty line [32]. However, the headcount ratio is considered as a crude poverty indicator. Sen defines the poverty as a deprivation of human capabilities [33]. He suggests that poverty should be a multidimensional problem. A multidimensional assessment of poverty takes into consideration various dimensions, such as income, education, health, and insurance [33-36]. However, the multidimensional assessment of poverty is largely dependent on the selected indicators. The proper indicators for multidimensional assessment are determined difficultly.

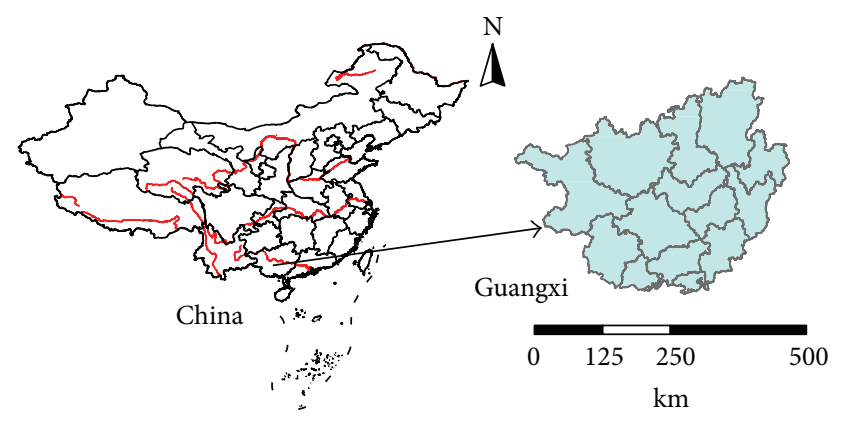

Figure 1: Location of Guangxi, China.

Foster et al. put forward the Foster-Greer-Thorbecke (FGT) method that measures poverty from incidence, depth, and severity $[37,38]$. The poverty incidence measures the percent of a population whose income or consumption is below the poverty line. The poverty depth describes the average shortfall of the total population from the poverty line. The poverty severity reveals the inequality among the poor, and it assigns more weight to the persons that fall far short of the poverty line rather than those that are closer. The FGT poverty measure contributes to poverty measurement by developing a suitably parametric family of measures having suitable characteristics and a plain structure that provide a clear and accessible instrument for policymakers [39]. Therefore, this article uses the FGT poverty measure to assess the poverty for quantifying poverty temporal changes in association with rural transition.

Using the case of Guangxi, one of the poorest provinces in China, this article aims to (1) assess the FGT poverty indices, (2) quantify the relationships between rural transition indicators and FGT poverty metrics, and (3) analyze the individual influences and joint influences of the components of rural transition on the FGT poverty indices.

\section{Study Area}

Guangxi Zhuang Autonomous Region, bordered with Vietnam, is located in the southeastern ring of the YunnanGuizhou Plateau in South West China (Figure 1). It is a typical mountainous region that is featured with karst landscapes. This region is located at low latitude area and has subtropical climate that is characterized by long, usually hot summer and short winter. The rainfall shows a summer peak in Guangxi, and the annual rainfall that increases gradually southward averages $1000-2800 \mathrm{~mm}$. Guangxi is one of the provinces most affected by meteorological disasters in China. Drought, flood, extreme heat or cold, and typhoon occur frequently in this place. The 2014 gross domestic product (GDP) of Guangxi ranks the thirteenth lowest nationwide. The poverty problem in Guangxi is pressing, and 5.38 million people are living below the official poverty line. A large proportion of farmers lack an essential amount of material possessions or money for livelihood in particular. It therefore offers a typical case to analyze the poverty issue in China. 
TABLE 1: Selected indicators of rural transition in Guangxi.

\begin{tabular}{|c|c|c|}
\hline Dimension & Variable & Definition \\
\hline \multirow{3}{*}{ Rural industrialization } & $\begin{array}{l}\text { Industrial total output of township and } \\
\text { village enterprises (ITOE) }\end{array}$ & $\begin{array}{l}\text { Ratio between total industrial output of rural township } \\
\text { and village enterprises and total output of primary } \\
\text { industry }\end{array}$ \\
\hline & $\begin{array}{l}\text { Proportion of persons employed in the } \\
\text { secondary industry in rural area (PPSR) }\end{array}$ & $\begin{array}{l}\text { Ratio between the number of persons employed in the } \\
\text { secondary industry and total employed persons in rural } \\
\text { area }\end{array}$ \\
\hline & Industry income proportion (IIP) & $\begin{array}{l}\text { Ratio between the industrial income per capita and } \\
\text { home business income per capita of farmer }\end{array}$ \\
\hline \multirow{4}{*}{ Regional urbanization } & Urban population proportion (UPP) & The ratio of urban population to total population \\
\hline & Secondary industry proportion (SIP) & $\begin{array}{l}\text { The ratio of gross product of secondary industry to } \\
\text { regional domestic product }\end{array}$ \\
\hline & Tertiary industry proportion (TIP) & $\begin{array}{l}\text { The ratio of gross product of tertiary industry to } \\
\text { regional domestic product }\end{array}$ \\
\hline & Urban-rural income gap (URIG) & $\begin{array}{l}\text { The ratio of rural per capita net income to urban per } \\
\text { capita disposable income }\end{array}$ \\
\hline \multirow{4}{*}{ Agriculture commercialization } & Tractor-plowed area (TPA) & Area of tractor-plowed agricultural land \\
\hline & Power of agricultural machinery (PAM) & Total power of agricultural machinery \\
\hline & Grain commercialization rate (GCR) & Grain commercialization rate in Guangxi \\
\hline & $\begin{array}{l}\text { Expenditure on fixed productive assets } \\
\text { per capita (EFPA) }\end{array}$ & $\begin{array}{l}\text { The amount of expenditure on fixed productive assets } \\
\text { per capita in rural households }\end{array}$ \\
\hline
\end{tabular}

\section{Data and Method}

3.1. Indicators Selection. Previous studies indicate that rural transition can be described from three aspects: rural industrialization, regional urbanization, and agricultural commercialization. In reference to this framework, I first select 20 indices to indicate the rural transition in Guangxi according to the literature review and data availability [25-27, 40-45]. Expert panel evaluation is then applied to judge these selected indicators. Only those receiving high scores are kept. Based on the experts' suggestions, two indicators are revised to describe rural industrialization and regional urbanization. Table 1 shows the final 11 indicators of rural transition. The main reasons for selecting these indicators are briefly described as follows.

First, the rural industrialization promotes the industrial growth in rural Guangxi [46]. Under rural industrialization, the output of rural industry increases and more farmers are employed by rural industry. Thus, increased rural industrialization tends to raise industrial income of farmers. I therefore choose three variables, namely, the industrial total output of township and village enterprises (ITOE), proportion of persons employed in the secondary industry in rural area (PPSR), and industry income proportion (IIP). Second, regional urbanization reflects a population shift from rural to urban areas [47]. Urbanization creates enormous impacts on local society and economy [41]. I therefore select four variables, including the urban population proportion (UPP), secondary industry proportion (SIP), tertiary industry proportion (TIP), and urban-rural income gap (URIG). Third, the agricultural commercialization stimulates a market orientation of farm production. Grain commercialization rate (GCR) is therefore chosen. Besides, the agricultural commercialization depends on the improvement of infrastructure for agricultural production [48]. I therefore select two variables of tractor-plowed area (TPA) and power of agricultural machinery (PAM). I also choose one more variable (expenditure on fixed productive assets per capita, EFPA) to indicate the mixing of farmers' asset endowment with the agricultural commercialization.

3.2. Data Collection. Data sources for indicators of rural transition include the Guangxi Statistical Yearbook, China Rural Statistical Yearbook, and China Statistical Yearbook of Rural Township and Village Enterprises. Descriptive statistics are shown in Appendix. Grouped rural per capita net incomes are used for evaluating the rural poverty from 1991 to 2010 in Guangxi. The data of rural per capita net incomes were obtained from the Guangxi Statistical Yearbook.

3.3. FGT Poverty Measure. According to Foster et al. (1984) and Foster et al. (2010) [37, 39], the general mathematical formula for FGT poverty measurement is expressed as

$$
\mathrm{FGT}_{a}=\frac{1}{n} \sum_{i=1}^{q}\left(\frac{z-y_{i}}{z}\right)^{a},
$$

where $a$ is a measure of poverty aversion; $n$ is the population size; $q$ is the number of poor farmers whose incomes or consumption level is below the poverty line; $y_{i}$ is individual incomes of farmers; $z$ is a poverty line. The larger the poverty aversion parameter $a$ is, the more important the poorest poor are [37]. With $a=0$, formula $\mathrm{FGT}_{0}$ reduces 
TABLE 2: Selected poverty line (unit: yuan).

\begin{tabular}{lcc}
\hline Year & Selected poverty line & Official poverty line \\
\hline 1991 & 329 & 304 \\
1992 & 366 & 317 \\
1993 & 443 & - \\
1994 & 554 & 440 \\
1995 & 723 & 530 \\
1996 & 852 & - \\
1997 & 938 & 640 \\
1998 & 986 & 635 \\
1999 & 1024 & 625 \\
2000 & 993 & 625 \\
2001 & 972 & 630 \\
2002 & 1007 & 627 \\
2003 & 1048 & 637 \\
2004 & 1153 & 668 \\
2005 & 1248 & 683 \\
2006 & 1386 & 693 \\
2007 & 1612 & 785 \\
2008 & 1845 & 1196 \\
2009 & 1990 & 1196 \\
2010 & 2272 & 1274 \\
\hline
\end{tabular}

The selected poverty line is 50 percent of the rural per capita net income in Guangxi.

The official poverty line was not publically accessible in 1993 and 1996.

to the headcount index $(H)$ which describes the poverty incidence. With $a=1$, formula $\mathrm{FGT}_{1}$ reduces to the poverty gap (PG) which describes the poverty depth. With $a=2$, formula $\mathrm{FGT}_{2}$ reduces to the squared poverty gap (SPG) which describes the poverty severity.

The official rural poverty line in China has been critiqued for being too low [49]. China's rural poverty line is considered as one of the lowest lines in the developing world. Actually, the relative poverty line can be set as 50 percent of the local mean income or consumption $[49,50]$. The mean income is sensitive to outliers in income distribution and in some cases may be not a robust measure; however, there is no official statistics about median income in China. Consequently, the mean income is widely selected in previous researches on poverty problem in China $[1,51]$. Therefore, in this study, the 50 percent of the rural per capita net income in Guangxi is selected as the poverty line for analyzing the rural poverty (Table 2). The selected poverty line which is more acceptable is higher than China's official poverty line. It is more suitable to reflect the actual poverty in rural Guangxi.

3.4. Statistical Analysis. Multivariate linear regression is conducted to characterize the relationship between rural poverty and rural transition in Guangxi. In particular, FGT poverty indices are dependent variables, and rural transition indicators are independent variables. All the variables are entered and the backward regression procedure is adopted to handle the multicollinearity problem.
In order to assess the relative influence of the three components of rural transition (rural industrialization, regional urbanization, and agriculture commercialization), the redundancy analysis (RDA) is applied to decompose the explained variances into several fractions [52-54]. Specifically, the variation which is indicated by total standard deviation is partitioned into the following different fractions: (1) individual contribution for one component of rural transition, (2) joint contributions for two components of rural transition, (3) joint contributions for three components of rural transition, and (4) unexplained total variations.

\section{Results}

4.1. Trend of Rural Poverty in Guangxi. Temporal changes of rural poverty in Guangxi from 1991 to 2010 are exhibited in Figure 2 . $H$ cannot be fitted comfortably since the distribution of $H$ has no significant increasing or decreasing trend. It denoted that the poverty incidence varies hugely in a short time, and the poverty incidence remains at a certain level. PG showed a significant cubic trend, signifying that the poverty depth has an increasing trend between 1991 and 2010. SPG also presented an increasing cubic trend. It denoted that the poverty severity has an upward trend, and the inequality among the poor farmers worsened during 1991 and 2010. All these results suggest that the rural poverty in Guangxi has not been greatly alleviated since 1991 .

4.2. Rural Transition Process of Guangxi. Temporal changes of rural transition indicators in Guangxi from 1991 to 2010 are shown in Figure 3. For indicators of rural industrialization, ITOE and IIP show a cubic trend, and PPSR presents a quadratic trend. ITOE increases first, decreases in between, and then increases again. PPSR has a decreasing trend until it bended upward. IIP first increases and then decreases after the bend point. It suggests that the rural industrialization has various characteristics in Guangxi. The scale of rural industry expands in 1990s, but it began to shrink at the beginning of the 21st century. And the rural industrialization does not raise the industrial income per capita continuously, though the rural industry employs more farmers. For indicators of regional urbanization, UPP presents an increasing linear trend, and SIP demonstrates an increasing cubic trend between 1991 and 2010. TIP first has an upward trend and then decreases after the bend point. URIG presents a decreasing linear trend. It denotes that the proportion of population in cities and towns has increased in Guangxi. The urbanrural income gap grows fast in Guangxi. It implies that the income inequality between farmers and urban residents still gradually worsens. Meanwhile, the tertiary industry does not develop continuously in Guangxi, and the decreasing trend of tertiary industry has negative impact on the regional urbanization. For indicators of agricultural commercialization, all the indicators, including TPA, PAM, GCR, and EFPA, present a growing trend, although GCR has an initial significant decreasing trend. It signifies that the agricultural commercialization has been accelerated between 1991 and 2010. The agricultural commercialization gradually improves 


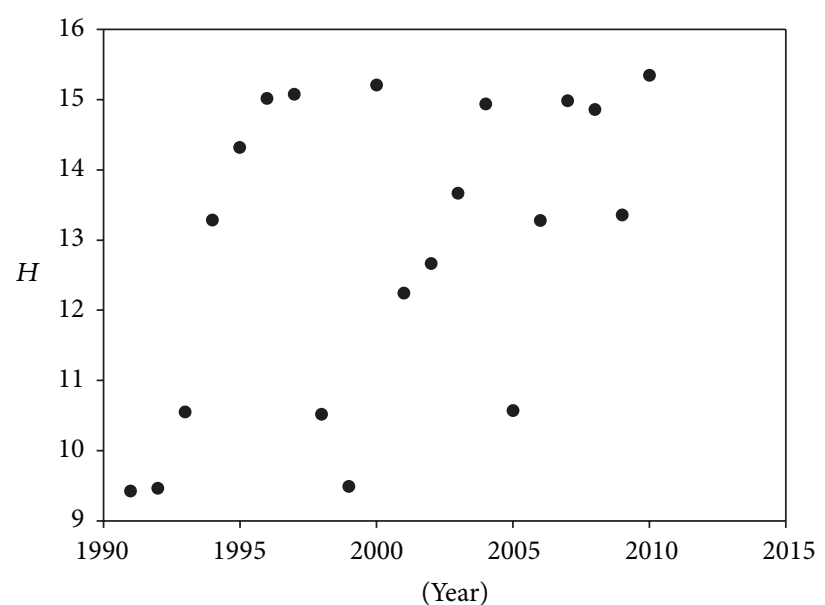

(a)

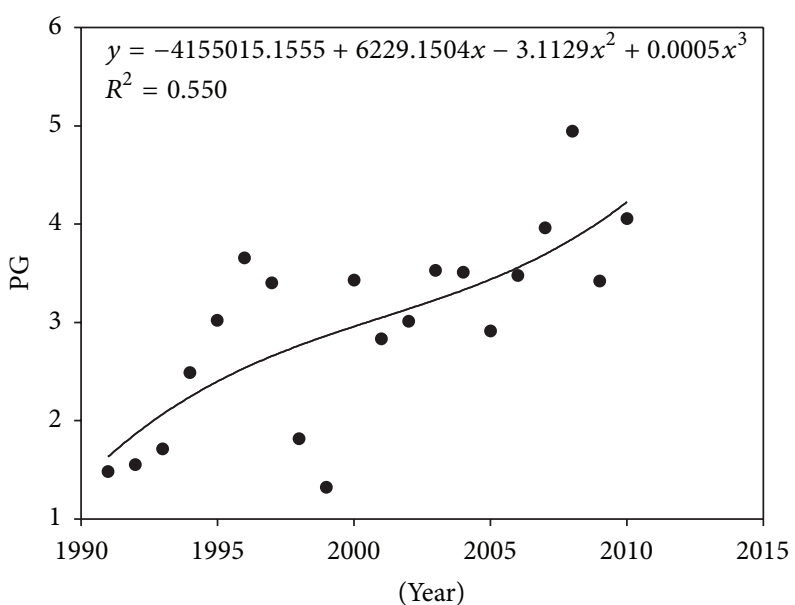

(b)

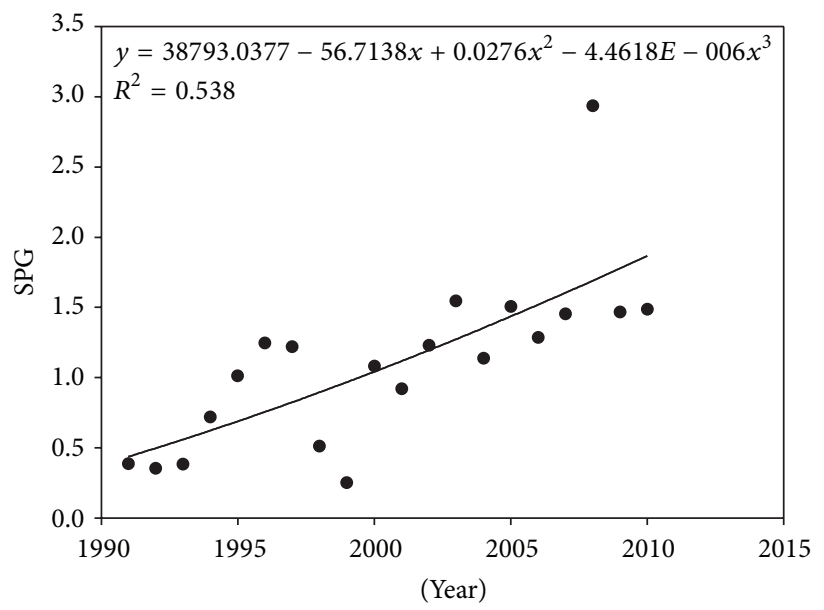

(c)

Figure 2: Temporal trend of rural poverty between 1991 and 2010 in Guangxi, China. Headcount index $(H)$, poverty gap (PG), and squared poverty gap (SPG).

the agricultural production in Guangxi, and the farmers expanded their participation in markets.

4.3. Temporal Changes of Rural Poverty in Association with Rural Transition. Relationships between rural poverty and rural transition are shown in Table 3. The regression models are capable of predicting the response of rural poverty temporal changes in response to rural transition, since over $90 \%$ of adjusted $R^{2}$ are explained. The exploratory rural transition indicators vary with the FGT poverty metrics. Between 1991 and 2010, IIP and SIP are positive contributors to the poverty incidence $(H)$, while URIG is a negative contributor to the poverty incidence $(H)$. The results denote that the improvement of industrial income per capita does not reduce the poverty incidence in Guangxi. Meanwhile, the different features of regional urbanization have opposite effects on the poverty incidence. The development of secondary industry also has a negative effect on the poverty incidence. But a narrowing of urban-rural income gap would cause the reduction in the poverty incidence. From 1991 to 2010, ITOE, IIP, and GCR present positive relationships with the poverty depth (PG); meanwhile, URIG presents negative relationships with the poverty depth (PG). It implies that the depth of poverty would be intensified by rural industrialization and agricultural commercialization in Guangxi. But it can be ameliorated by narrowing urban-rural income gap. TIP and EFPA are correlated with the poverty severity positively (SPG), while URIG and PAM are correlated with the poverty severity negatively (SPG). It suggests that the inequality between the poor farmers worsens since the growth of regional urbanization in respect to tertiary industry proportion, but the inequality could be reduced by narrowing the urban-rural income gap. Meanwhile, the growth in agricultural commercialization owing to expenditure on fixed productive assets per capita poses an extra challenge for eliminating poverty severity. However, increases in agriculture commercialization owing to power of agricultural machinery can ease the poverty severity.

Table 4 shows the relative influences of different components of rural transition on rural poverty. It can be 


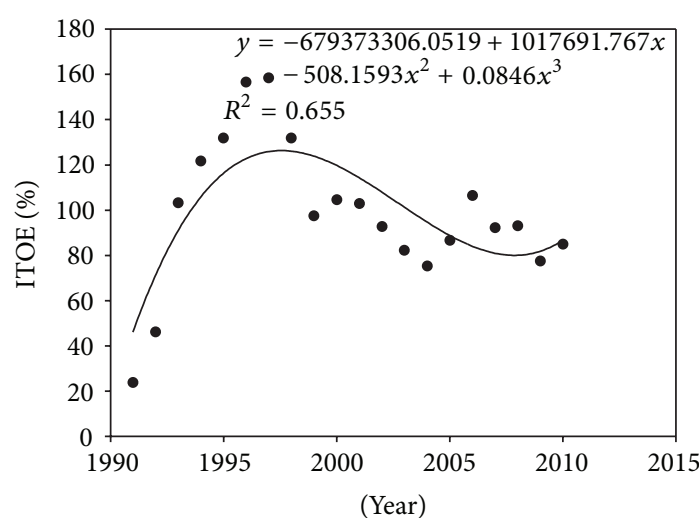

(a)

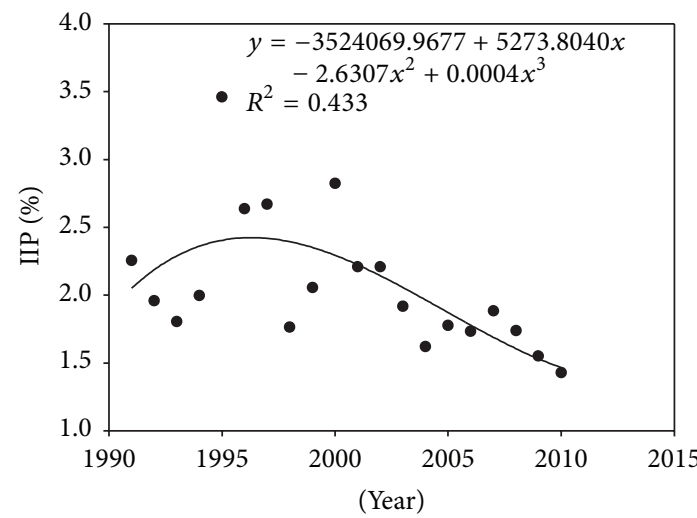

(c)

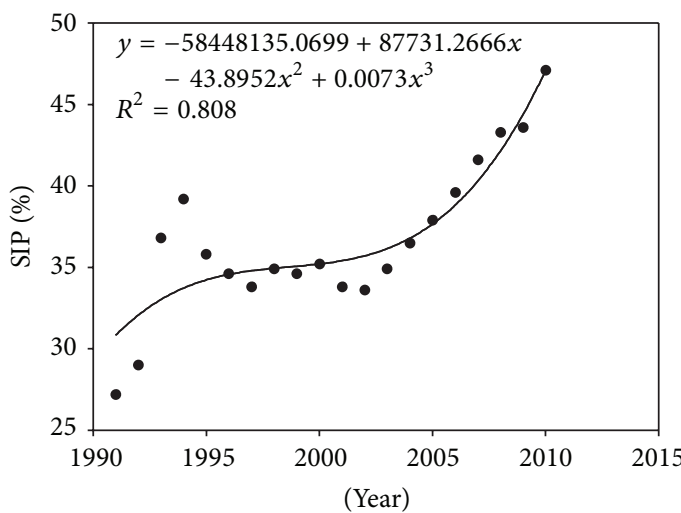

(e)

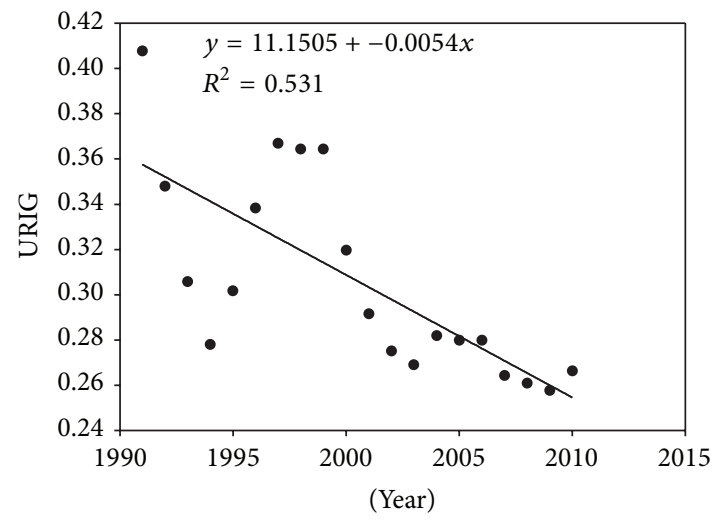

(g)

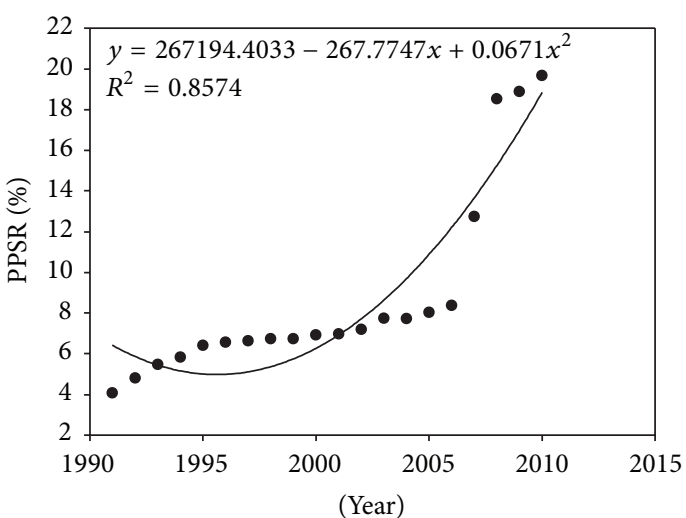

(b)

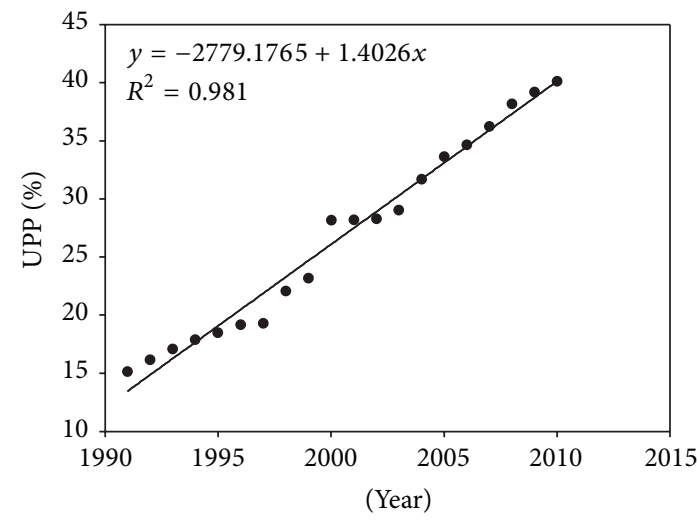

(d)

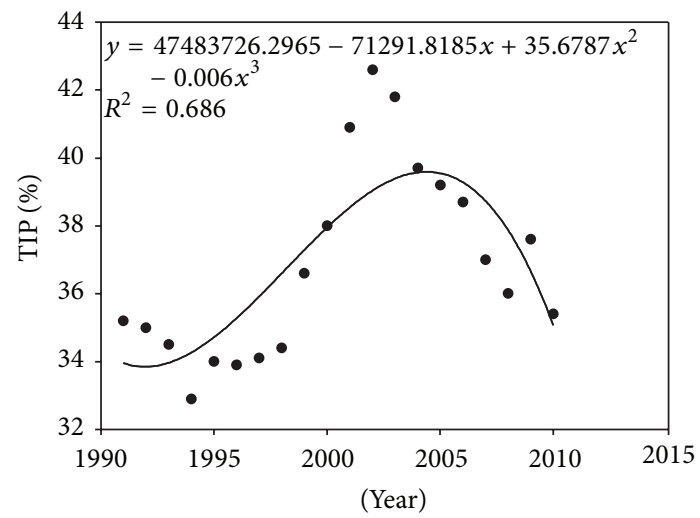

(f)

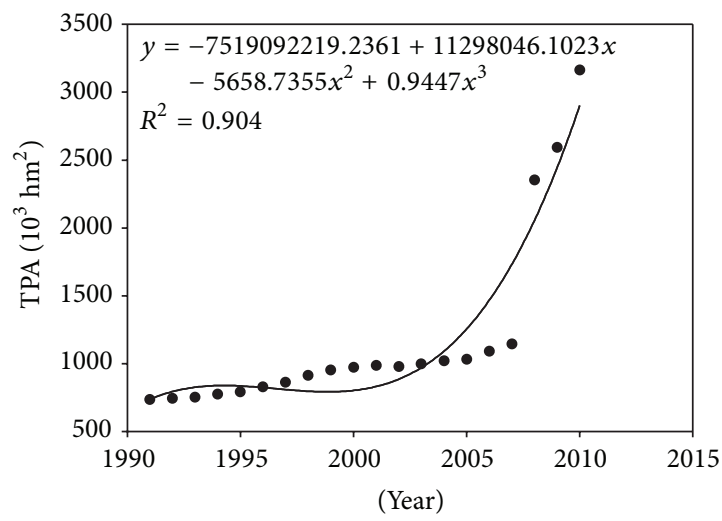

(h)

FIGURE 3: Continued. 


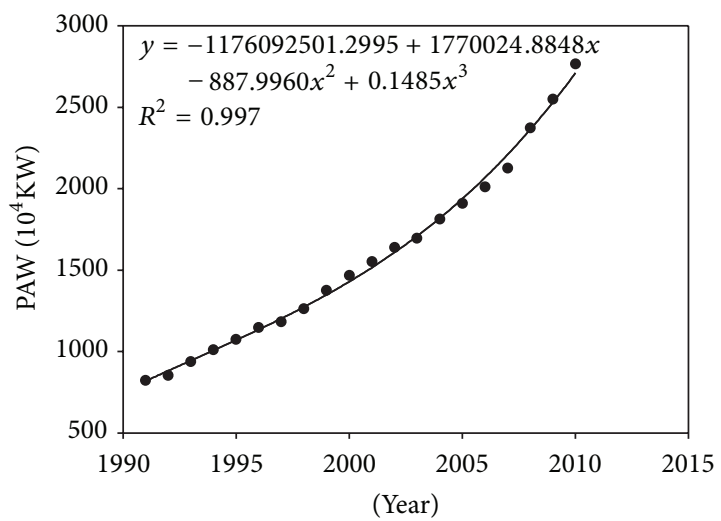

(i)

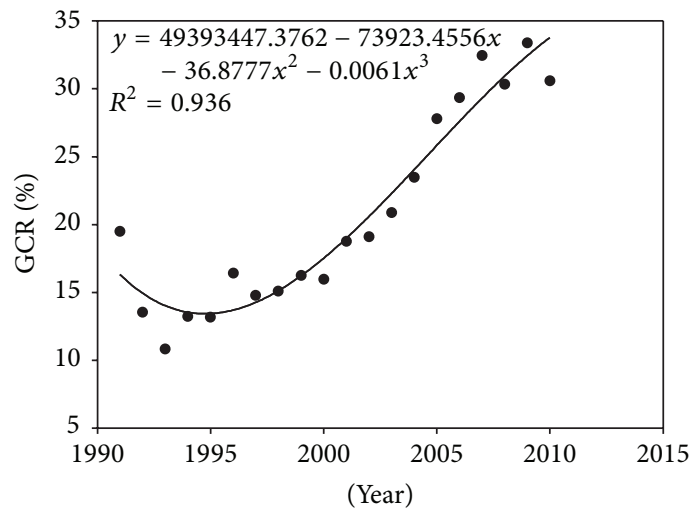

(j)

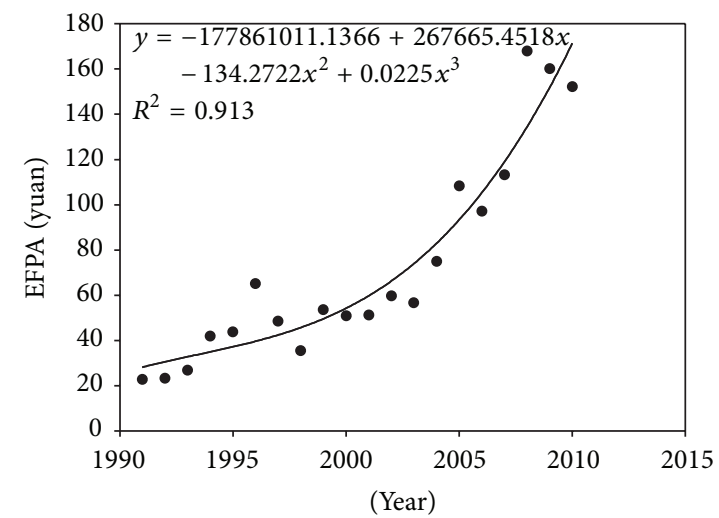

(k)

Figure 3: Temporal trend of rural transition indicators between 1991 and 2010 in Guangxi, China: industrial total output of township and village enterprises (ITOE), proportion of persons employed in the secondary industry in rural area (PPSR), industry income proportion (IIP), urban population proportion (UPP), secondary industry proportion (SIP), tertiary industry proportion (TIP), urban-rural income gap (URIG), tractor-plowed area (TPA), power of agricultural machinery (PAM), grain commercialization rate (GCR), and expenditure on fixed productive assets per capita (EFPA).

seen that the individual influence of rural industrialization is higher than that of regional urbanization and agricultural commercialization. Besides, the joint influences of rural industrialization, regional urbanization, and agriculture commercialization are the strongest. These results imply that the evolution of rural poverty should be more subjected to rural industrialization and regional urbanization.

\section{Discussion and Policy Implications}

The multivariable linear regressions could provide some important quantitative insights, regarding the evolution of rural poverty under rural transition in Guangxi. The positive coefficient for IIP reveals the strong correlation between the rural industrialization and increasing poverty incidence. The growth of ratio between the industrial income per capita and home business income per capita of farmers is unlikely to sever as a motor of decreases in poverty incidence [55]. The increasing IIP in Guangxi does not couple with the rising income per farmer. The low-income farmers are not endowed with capitals to benefit from the increasing industrial income during rural industrialization [56]. Meanwhile, the positive coefficient for SIP and negative coefficient for URIG suggest that the regional urbanization has different impacts on the poverty incidence. The growing secondary industry has driven the farmers to fall below the poverty line. It implies that the growing secondary industry does not trickle down to the poor, and the accumulation of wealth due to secondary industry is not beneficial for the low-income farmers in Guangxi [57]. The main reason is that a large proportion of poor farmers live in the karst mountain areas which are covered by soluble rocks. These karst regions always suffer from insufficient supply of surface water [58]. Therefore, the geographic condition in the karst mountain areas is not suitable for developing the secondary industry, especially for major industry sector and construction sector. The rapid growth of secondary industry is concentrated in the urban cities in Guangxi, but it cannot benefit the poor farmers since it is not the trickle-down growth. In contrast, the reduction in income inequality between farmers and urban residents can improve the poverty incidence. Yao also finds that rising income inequality has a critical opposite effect on the income growth which is key factor in reducing poverty incidence [10]. 
TABLE 3: Relationships between FGT poverty metrics and rural transition indicators.

\begin{tabular}{lccc}
\hline Dependent variables & Exploratory variables & Regression & ${\text { Adjusted } R^{2}}^{2}$ \\
\hline$H$ & IIP, SIP, URIG & $Y=2.560 \times \mathrm{IIP}+0.299 \times \mathrm{SIP}-11.026 \times \mathrm{URIG}$ & $0.987^{* * *}$ \\
PG & ITOE, IIP, URIG, GCR & $Y=0.011 \times \mathrm{ITOE}+0.747 \times \mathrm{IIP}-6.126 \times \mathrm{URIG}+0.109 \times \mathrm{GCR}$ & $0.971^{* * *}$ \\
SPG & TIP, URIG, PAM, EFPA & $Y=0.061 \times \mathrm{TIP}-3.115 \times \mathrm{URIG}-0.001 \times \mathrm{PAM}+0.021 \times \mathrm{EFPA}^{*}$ & $0.925^{* * *}$ \\
\hline
\end{tabular}

*** $p<0.01$.

Industrial total output of township and village enterprises (ITOE), industry income proportion (IIP), secondary industry proportion (SIP), tertiary industry proportion (TIP), urban-rural income gap (URIG), power of agricultural machinery (PAM), grain commercialization rate (GCR), and expenditure on fixed productive assets per capita (EFPA).

TABLE 4: Relative influences of different components of rural transition on rural poverty (\%).

\begin{tabular}{lc}
\hline Component & $\begin{array}{c}\text { Rural } \\
\text { poverty }\end{array}$ \\
\hline Rural industrialization & 13.80 \\
Regional urbanization & 6.10 \\
Agricultural commercialization & 3.20 \\
Rural industrialization \& regional urbanization & 3.49 \\
Rural industrialization \& agricultural commercialization & 8.28 \\
Regional urbanization \& agricultural commercialization & 5.01 \\
Rural industrialization \& regional urbanization \& & 14.31 \\
agricultural commercialization & 54.18 \\
\hline Total explained & 45.82 \\
\hline Unexplained total variation & \\
\hline
\end{tabular}

Indicators of rural industrialization including ITOE and IIP have the positive coefficients for the poverty depth. It implies that increasing total resources cannot eradicate poverty of farmers during the rapid rural industrialization. The expansion of rural industry raises the greater inequality among farmers [27]. The poor farmers fail to have the opportunities to bring them all out of poverty in the rural industrialization, given the inequity policy, lack of natural resources, and lack of access to education [5, 55, 59]. But the regional urbanization brings about a decreased depth of poverty owing to narrowing urban-rural income gap because of the negative coefficients of URIG. Since the open-door reform in the late 1970s, Chinese government has encouraged some people to get rich first by adopting "getting rich first" policy [60]. But it causes a serious inequality in China. The result suggests that the urban-rural income inequality leads to the unequal distribution of incomes between farmers and urban residents. The high degree of income equal distribution can help poor farmers to narrow the gap between income and poverty line $[19,56]$. The agricultural commercialization cannot reduce the depth of poverty for the sake of the positive coefficients of GCR. It implies that the poor farmers cannot share the gains from the grain commercialization because the farmers' livelihood assets, such as farmland, technology, and labors, are not sufficient to obtain farm surpluses which can help to raise their income. However, nonpoverty farmers benefit from the grain commercialization, and they could raise their agricultural income during the process of grain commercialization. Therefore, the income gap between the poor farmers and nonpoverty farmers is enlarged by the agricultural commercialization in Guangxi.

The positive influence of TIP on the poverty severity denotes that the poorest farmers cannot substantially benefit from the development of tertiary industry. The inequality among the poor farmers does not improve since the income distribution among the poor is still unequal [61]. The poorest farmers are further away from the poverty line than the other poor farmers since they obtain smaller benefits from the tertiary industry. The regional urbanization accounts for more equal distribution among the farmers given the negative influence of URIG on the poverty severity. It indicates that the poverty can be alleviated when the gap between the farmers and urban residents is narrowed [62]. The agricultural commercialization can improve poverty severity by increasing power of agricultural machinery. However, it makes poverty severity worse simultaneously due to growing expenditure on fixed productive assets per capita. The increasing power of agricultural machinery enhances farm productivity in Guangxi, and the benefits which are gained from agricultural commercialization to the poor farmers are not confined to those near the poverty line [63]. Although the fixed productive assets of rural households have important impacts on the agricultural productivity [64], the poorer farmers have low willingness to pay for fixed productive assets [22]. Therefore, the poorer farmers cannot benefit from the increasing fixed productive assets. The inequality among the poor farmers does not get ameliorative by raising the expenditure on fixed productive assets per capita in rural households. And the farmers who have surplus cash can obtain more benefits in the process of agricultural commercialization. It may exacerbate the poverty severity in Guangxi.

Comparing the relative influence of the three components of rural transition, the results show that rural industrialization is the most influential factor for evolution of rural poverty. It makes sense in that the development of local nonfarm industrialization which affects the farmers' non-farm income and off-farm employ is key factor for the evolution of rural poverty, although it has the negative impact on the poverty alleviation. I also discover that the joint influences of rural industrialization and agricultural commercialization are the strongest. Consequently, the rural transition which is considered as a road to poverty alleviation is heavily determined by rural industrialization.

This paper also provides some implications for policies. The rural industrialization has negative impact on the poverty alleviation in Guangxi. The important point to solve this 
problem is that the farmers' endowments are enhanced to help them gain more benefits from rural industrialization. Thus, the government's priority is to provide the public investments in education, vocational training, and infrastructure for poor farmers [51, 65]. Meanwhile, the specific enterprises in rural township and village should be selected to fit the local farmers' endowments, especially for the poorest farmers. The rural Guangxi should pay more attention to the development of labor-intensive enterprises. The labor-intensive enterprise sought for more effective and sustainable use of local natural resources.

The growth process of industries in regional urbanization cannot be classifiable as pro-poor. It implies that the benefits from the growth process of industries do not trickle down from the rich to the poor. The promoting pro-poor growth of industries requires policies and programs that are deliberately biased in favor of the poor farmers so that the poor farmers benefit proportionally more than the rich farmers [66]. For example, the policies should be in favor of the migration of poor farmers to secondary industry in urban areas since the rich farmers who are relatively skilled labor have more opportunities to migrate to secondary industry in the growth process of industries, and the rich farmers gain the large proportional benefits from the growth of secondary industry. A narrowing of urban-rural income gap in the process of regional urbanization is important for improving poverty incidence, poverty depth, and poverty severity. The policies for narrowing urban-rural income gap require a fundamental change of government attitude that is urban biased [10]. The price scissors between industrial and agricultural products still affect the wealth distribution between farmers and urban residents. The main methods to narrow price scissors are to increase the price of farm products and nurturing agriculture by industry. In addition, the wages of migrant farmers in urban areas are lower than the wages of urban residents in the long term. The government ought to choose to accelerate the growth rate of the wages of migrant farmers. The increasing wages can raise the incomes of poor farmers and rich farmers, and the poorest farmers can obtain more benefits from the regional urbanization [67].

The agriculture commercialization should provide farmers with the new technologies, such as agricultural machinery [68]. The poorest farmers can obtain more benefits from these new technologies. Therefore, the important strategy is to encourage government to provide more technological support for the poorest farmer. Increasing grain commercialization rate and expenditure on fixed productive assets per capita cannot improve the poverty depth and poverty severity. It implies that, in order to alleviate poverty, the grain market should promote poor farmers' productivity growth and the poor farmers also should have more opportunities to increase their fixed productive assets.

\section{Conclusions}

This study characterizes the temporal changes of rural poverty including poverty incidence, poverty depth, and poverty severity in Guangxi using FGT poverty measure. And
TABLE 5: Statistical description of indicators of rural transition.

\begin{tabular}{lcccccc}
\hline Variable & Unit & Obs. & Min. & Max. & Mean & Std. dev. \\
\hline ITOE & $\%$ & 20 & 23.830 & 158.450 & 98.475 & 32.353 \\
PPSR & $\%$ & 20 & 4.090 & 19.670 & 8.810 & 4.722 \\
IIP & $\%$ & 20 & 1.430 & 3.460 & 2.076 & 0.497 \\
UPP & $\%$ & 20 & 15.150 & 40.110 & 26.793 & 8.380 \\
SIP & $\%$ & 20 & 27.200 & 47.100 & 36.650 & 4.778 \\
TIP & $\%$ & 20 & 32.900 & 42.600 & 36.875 & 2.842 \\
URIG & - & 20 & 0.260 & 0.410 & 0.307 & 0.044 \\
TPA & $10^{3} \mathrm{hm}^{2}$ & 20 & 735.100 & 3163.700 & 1184.220 & 678.904 \\
PAM & $10^{4} \mathrm{KW}$ & 20 & 824.400 & 2767.700 & 1579.230 & 572.850 \\
GCR & $\%$ & 20 & 10.840 & 33.390 & 20.742 & 7.322 \\
EFPA & Yuan & 20 & 22.730 & 167.880 & 72.661 & 45.361 \\
\hline
\end{tabular}

it presents the rural transition process described from three aspects including rural industrialization, regional urbanization, and agriculture commercialization in Guangxi. Then, the evolution of rural poverty under rural transition during 1991-2010 in Guangxi is analyzed. Results of multivariate linear regression reveal that IIP and SIP are positive contributors to the poverty incidence, while URIG is negative contributor to the poverty incidence. ITOE, IIP, and GCR present positive relationships with the poverty depth; meanwhile, URIG presents negative relationships with the poverty depth. TIP and EFPA correlate with the poverty severity positively, while URIG and PAM correlate with the poverty severity negatively. Results of redundancy analysis show that individual influence of rural industrialization is higher than that of regional urbanization and agriculture commercialization. And the joint influences of rural industrialization, regional urbanization, and agriculture commercialization are the strongest. In order to improve negative influences of the current rural transition, the government should pay more attention to the improvement of the poor farmers' endowments by increasing public investments in education, vocational training, and infrastructure for poor farmers, promoting pro-poor growth of industries in rural areas and urban areas, changing the government attitude that is urban biased, and promoting poor farmers' productivity growth.

\section{Appendix}

See Table 5.

\section{Competing Interests}

The author declares that there are no competing interests regarding the publication of this paper.

\section{Acknowledgments}

This research has received financial support by Zhi-Jiang Young Scholar Program of Social Science of Zhejiang Province under Grant no. 16ZJQN026YB, by National Natural Science Foundation of China under Grant no. 71403235, 
and by Zhejiang Provincial Natural Science Foundation of China under Grant no. LQ14G030016.

\section{References}

[1] L. Caizhen, "Who is poor in China? A comparison of alternative approaches to poverty assessment in Rural Yunnan," The Journal of Peasant Studies, vol. 37, no. 2, pp. 407-428, 2010.

[2] L. Meng, "Evaluating China's poverty alleviation program: a regression discontinuity approach," Journal of Public Economics, vol. 101, no. 1, pp. 1-11, 2013.

[3] D. Benjamin, L. Brandt, and J. Giles, "The evolution of income inequality in rural China," Economic Development and Cultural Change, vol. 53, no. 4, pp. 769-824, 2005.

[4] J. Yu, "Multidimensional poverty in China: findings based on the CHNS," Social Indicators Research, vol. 112, no. 2, pp. 315336, 2013.

[5] T. Glauben, T. Herzfeld, S. Rozelle, and X. Wang, "Persistent poverty in rural China: where, why, and how to escape?" World Development, vol. 40, no. 4, pp. 784-795, 2012.

[6] M. Ravallion and S. Chen, "China's (uneven) progress against poverty," Journal of Development Economics, vol. 82, no. 1, pp. $1-42,2007$.

[7] World Bank, Poverty \& Equity, World Bank, Washington, DC, USA, 2015, http://povertydata.worldbank.org/poverty/country/ CHN.

[8] Q.-Q. Liu, M. Yu, and X.-L. Wang, "Poverty reduction within the framework of SDGs and Post-2015 development agenda," Advances in Climate Change Research, vol. 6, no. 1, pp. 67-73, 2015.

[9] C.-C. Goh, X. Luo, and N. Zhu, "Income growth, inequality and poverty reduction: a case study of eight provinces in China," China Economic Review, vol. 20, no. 3, pp. 485-496, 2009.

[10] S. Yao, "Economic growth, income inequality and poverty in China under economic reforms," The Journal of Development Studies, vol. 35, no. 6, pp. 104-130, 1999.

[11] F. H. G. Ferreira, P. G. Leite, and M. Ravallion, "Poverty reduction without economic growth? Explaining Brazil's poverty dynamics, 1985-2004," Journal of Development Economics, vol. 93, no. 1, pp. 20-36, 2010.

[12] J. E. Foster and M. E. Santos, "Measuring chronic poverty," in Poverty and Social Exclusion: New Methods of Analysis, G. Betti and A. Lemmi, Eds., pp. 143-165, Routledge, Abington, UK, 2013.

[13] B. Cheli and G. Betti, "Fuzzy analysis of poverty dynamics on an Italian Pseudo Panel, 1985-1994," Metron, vol. 57, pp. 83-103, 1999.

[14] V. Verma, G. Betti, and F. Gagliardi, "Fuzzy measures of longitudinal poverty in a comparative perspective," Social Indicators Research, 2015.

[15] J.-Y. Duclos, A. Araar, and J. Giles, "Chronic and transient poverty: measurement and estimation, with evidence from China," Journal of Development Economics, vol. 91, no. 2, pp. 266-277, 2010.

[16] D. Hulme and A. Shepherd, "Conceptualizing chronic poverty," World Development, vol. 31, no. 3, pp. 403-423, 2003.

[17] M. Hoy and B. Zheng, "Measuring lifetime poverty," Journal of Economic Theory, vol. 146, no. 6, pp. 2544-2562, 2011.

[18] C. Gradín, C. Del Río, and O. Cantó, "Measuring poverty accounting for time," Review of Income and Wealth, vol. 58, no. 2, pp. 330-354, 2012.
[19] S. Yao, Z. Zhang, and L. Hanmer, "Growing inequality and poverty in China," China Economic Review, vol. 15, no. 2, pp. 145-163, 2004.

[20] M. R. Carter and C. B. Barrett, "The economics of poverty traps and persistent poverty: an asset-based approach," The Journal of Development Studies, vol. 42, no. 2, pp. 178-199, 2006.

[21] J. D. Sachs, A. D. Mellinger, and J. L. Gallup, “The geography of poverty and wealth," Scientific American, vol. 284, no. 3, pp. 70-75, 2001.

[22] J. Jalan and M. Ravallion, "Geographic poverty traps? A micro model of consumption growth in rural China," Journal of Applied Econometrics, vol. 17, no. 4, pp. 329-346, 2002.

[23] K.-M. Chen and T.-M. Wang, "Determinants of poverty status in Taiwan: a multilevel approach," Social Indicators Research, vol. 123, no. 2, pp. 371-389, 2015.

[24] M. Cancian and D. Reed, "Changes in family structure: implications for poverty and related policy," Focus, vol. 21, no. 2, pp. $21-26,2000$.

[25] T. S. Jayne, T. Yamano, M. T. Weber et al., "Smallholder income and land distribution in Africa: implications for poverty reduction strategies," Food Policy, vol. 28, no. 3, pp. 253-275, 2003.

[26] A. Nyberg and S. Rozelle, Accelerating China's Rural Transformation, World Bank, Washington, DC, USA, 1999.

[27] S. Rozelle, "Rural industrialization and increasing inequality: emerging patterns in China/s reforming economy," Journal of Comparative Economics, vol. 19, no. 3, pp. 362-391, 1994.

[28] S. Rozelle, C. E. Pray, and J. Huang, "Agricultural research policy in China: testing the limits of commercialization-led reform," Comparative Economic Studies, vol. 39, no. 2, pp. 37-71, 1997.

[29] X.-R. Wang, E. C.-M. Hui, C. Choguill, and S.-H. Jia, "The new urbanization policy in China: which way forward?" Habitat International, vol. 47, pp. 279-284, 2015.

[30] H. You, "Impact of urbanization on pollution-related agricultural input intensity in Hubei, China," Ecological Indicators, vol. 62, pp. 249-258, 2016.

[31] S. Su, Y. Hu, F. Luo, G. Mai, and Y. Wang, "Farmland fragmentation due to anthropogenic activity in rapidly developing region," Agricultural Systems, vol. 131, pp. 87-93, 2014.

[32] S. D. Tendulkar and L. R. Jain, "Economic reforms and poverty," Economic and Political Weekly, vol. 30, no. 23, pp. 1373-1377, 1995.

[33] A. Sen, "Poverty: an ordinal approach to measurement," Econometrica, vol. 44, no. 2, pp. 219-231, 1976.

[34] K. Labar and F. Bresson, "A multidimensional analysis of poverty in China from 1991 to 2006," China Economic Review, vol. 22, no. 4, pp. 646-668, 2011.

[35] S. Alkire and J. Foster, "Counting and multidimensional poverty measurement," Journal of Public Economics, vol. 95, no. 7-8, pp. 476-487, 2011.

[36] J. Deutsch and J. Silber, "Measuring multidimensional poverty: an empirical comparison of various approaches," Review of Income and Wealth, vol. 51, no. 1, pp. 145-174, 2005.

[37] J. Foster, J. Greer, and E. Thorbecke, "A class of decomposable poverty measures," Econometrica, vol. 52, no. 3, pp. 761-766, 1984.

[38] P. Glewwe, M. Gragnolati, and H. Zaman, "Who gained from Vietnam's boom in the 1990s?" Economic Development and Cultural Change, vol. 50, no. 4, pp. 773-792, 2002. 
[39] J. Foster, J. Greer, and E. Thorbecke, "The Foster-GreerThorbecke (FGT) poverty measures: 25 years later," The Journal of Economic Inequality, vol. 8, no. 4, pp. 491-524, 2010.

[40] A. Mukherjee and X. Zhang, "Rural industrialization in China and India: role of policies and institutions," World Development, vol. 35, no. 10, pp. 1621-1634, 2007.

[41] H. You, "Quantifying the coordinated degree of urbanization in Shanghai, China," Quality \& Quantity, vol. 50, no. 3, pp. 12731283, 2016.

[42] H. You, "Quantifying megacity growth in response to economic transition: a case of Shanghai, China," Habitat International, vol. 53, pp. 115-122, 2016.

[43] H. You and X. Zhang, "Ecoefficiency of intensive agricultural production and its influencing factors in China: an application of DEA-Tobit analysis," Discrete Dynamics in Nature and Society, vol. 2016, Article ID 4786090, 14 pages, 2016.

[44] S. Su, X. Ma, and R. Xiao, "Agricultural landscape pattern changes in response to urbanization at ecoregional scale," Ecological Indicators, vol. 40, pp. 10-18, 2014.

[45] P. L. Pingali and M. W. Rosegrant, "Agricultural commercialization and diversification: processes and policies," Food Policy, vol. 20, no. 3, pp. 171-185, 1995.

[46] J. Y. Lin and Y. Yao, "Chinese rural industrialization in the context of the East Asian miracle," in Rethinking the East Asian Miracle, J. E. Stigilitz and S. Yusuf, Eds., pp. 143-195, Oxford University Press, New York, NY, USA, 2001.

[47] S. Su, D. Li, Y. Hu, R. Xiao, and Y. Zhang, "Spatially nonstationary response of ecosystem service value changes to urbanization in Shanghai, China," Ecological Indicators, vol. 45, pp. 332-339, 2014.

[48] C. A. Okezie, J. Sulaiman, and A. C. Nwosu, "Farm-level determinants of agricultural commercialization," International Journal of Agriculture and Forestry, vol. 2, no. 2, pp. 1-5, 2012.

[49] X. Wang, J. Liu, S. Yao, and X. Xin, "China’s rural poverty line and the determinants of rural poverty," China Agricultural Economic Review, vol. 1, no. 3, pp. 283-300, 2009.

[50] J. E. Foster, "Absolute versus Relative Poverty," American Economic Review, vol. 88, no. 2, pp. 335-341, 1998.

[51] S. Fan, L. Zhang, and X. Zhang, "Reforms, investment, and poverty in rural China," Economic Development and Cultural Change, vol. 52, no. 2, pp. 395-421, 2004.

[52] X. Li, W. Zhou, and Z. Ouyang, "Forty years of urban expansion in Beijing: what is the relative importance of physical, socioeconomic, and neighborhood factors?" Applied Geography, vol. 38, no. 1, pp. 1-10, 2013.

[53] R. K. Heikkinen, M. Luoto, M. Kuussaari, and J. Pöyry, "New insights into butterfly-environment relationships using partitioning methods," Proceedings of the Royal Society of London B: Biological Sciences, vol. 272, no. 1577, pp. 2203-2210, 2005.

[54] M. J. Anderson and N. A. Gribble, "Partitioning the variation among spatial, temporal and environmental components in a multivariate data set," Australian Journal of Ecology, vol. 23, no. 2, pp. 158-167, 1998.

[55] S. Haggblade, P. Hazell, and T. Reardon, "The rural non-farm economy: prospects for growth and poverty reduction," World Development, vol. 38, no. 10, pp. 1429-1441, 2010.

[56] M. Ravallion, "Growth, inequality and poverty: looking beyond averages," World Development, vol. 29, no. 11, pp. 1803-1815, 2001.

[57] P. Aghion and P. Bolton, "A theory of trickle-down growth and development," The Review of Economic Studies, vol. 64, no. 2, pp. 151-172, 1997.
[58] Z. Yang, Y. Liu, G. Bao, Z. Li, and Y. He, "Rehabilitation and sustainable use pattern of rocky-desertified land in Southwest China's poverty-stricken karst mountainous areas," Journal of Mountain Science, vol. 3, no. 3, pp. 237-246, 2006.

[59] R. Kanbur, "Economic policy, distribution and poverty: the nature of disagreements," World Development, vol. 29, no. 6, pp. 1083-1094, 2001.

[60] C. C. Fan, "China's eleventh five-year plan (2006-2010): from 'getting rich first' to 'common prosperity"' Eurasian Geography and Economics, vol. 47, no. 6, pp. 708-723, 2006.

[61] B. Milanovic, "Income, inequality and poverty during the transition: a survey of the evidence," MOST: Economic Policy in Transitional Economies, vol. 6, no. 1, pp. 131-147, 1996.

[62] H. Long, J. Zou, and Y. Liu, "Differentiation of rural development driven by industrialization and urbanization in eastern coastal China," Habitat International, vol. 33, no. 4, pp. 454-462, 2009.

[63] G. Datt and M. Ravallion, "Farm productivity and rural poverty in India," Journal of Development Studies, vol. 34, no. 4, pp. 6285, 1998.

[64] G. Feder, L. J. Lau, J. Y. Lin, and Xiaopeng Luo, “The determinants of farm investment and residential construction in postreform China," Economic Development and Cultural Change, vol. 41, no. 1, pp. 1-26, 1992.

[65] X. Zhang and S. Fan, "Public investment and regional inequality in rural China," Agricultural Economics, vol. 30, no. 2, pp. 89100, 2004.

[66] N. Kakwani and E. M. Pernia, "What is pro-poor growth?" Asian Development Review, vol. 18, no. 1, pp. 1-16, 2000.

[67] J. Knight and L. Song, "Chinese peasant choices: migration, rural industry or farming," Oxford Development Studies, vol. 31, no. 2, pp. 123-148, 2003.

[68] T. S. Jayne, S. Haggblade, N. Minot, and S. Rashid, "Agricultural commercialization, rural transformation and poverty reduction: what have we learned about how to achieve this?" in Proceedings of the African Agricultural Markets Programme Policy Symposium, Synthesis Report, Alliance for Commodity Trade in Eastern and Southern Africa, Kigali, Rwanda, April 2011. 


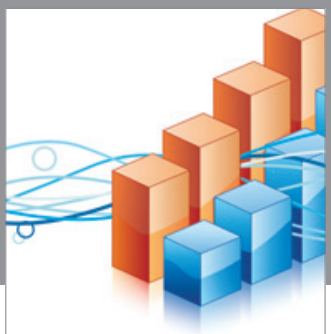

Advances in

Operations Research

vatem alat4

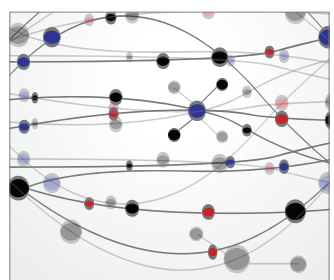

\section{The Scientific} World Journal
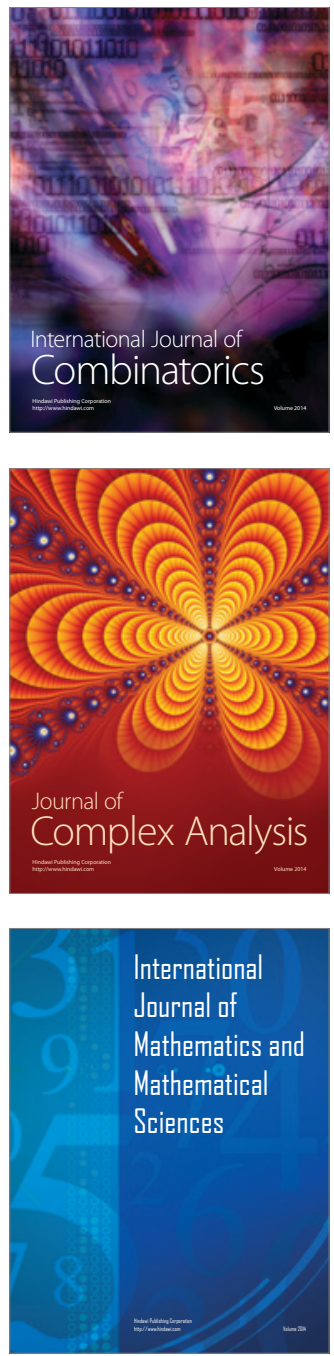
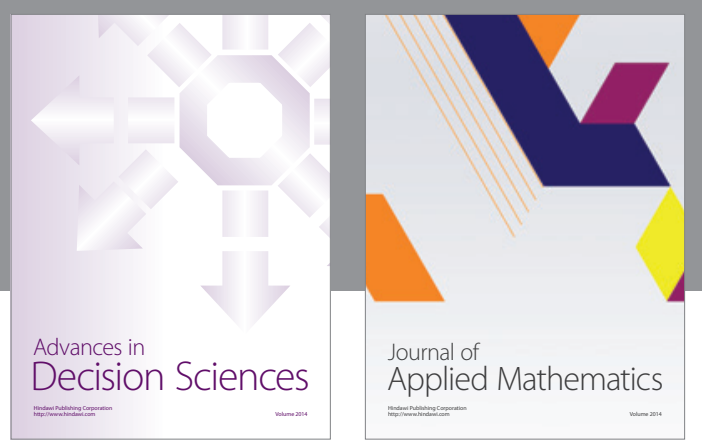

Algebra

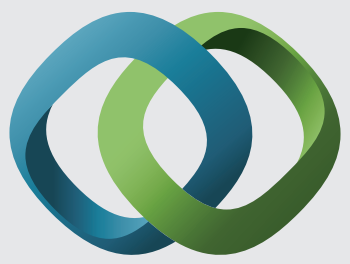

\section{Hindawi}

Submit your manuscripts at

http://www.hindawi.com
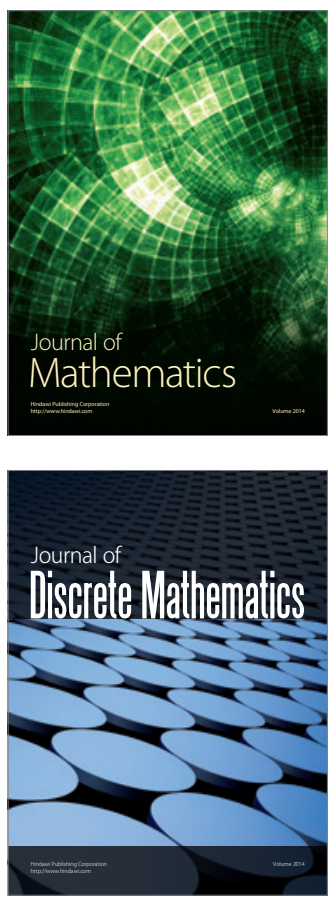

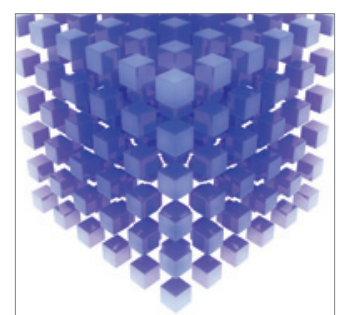

Mathematical Problems in Engineering
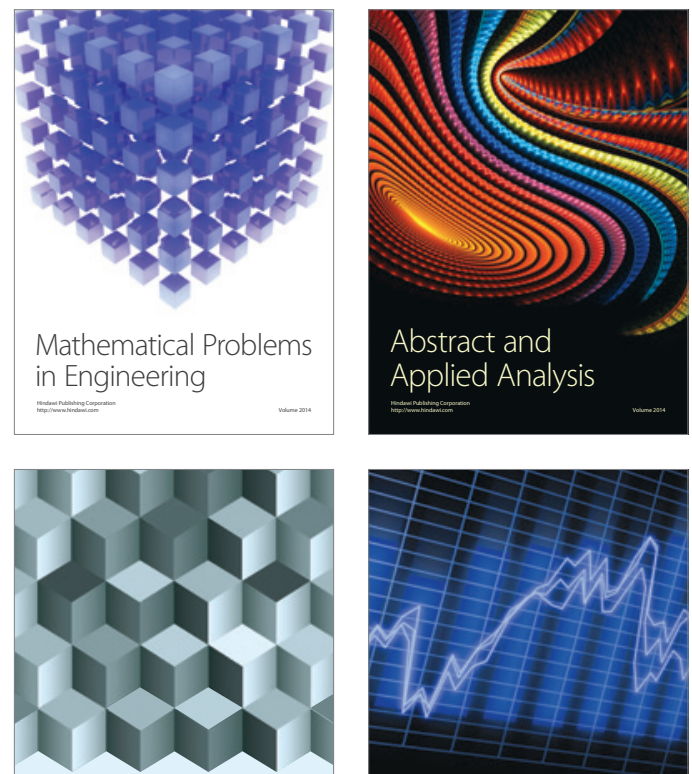

Journal of

Function Spaces

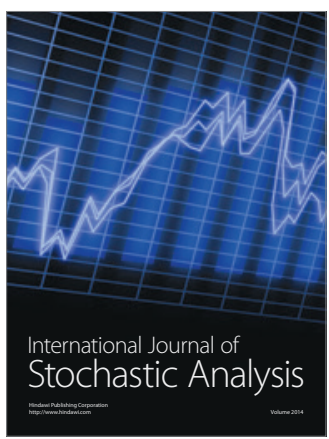

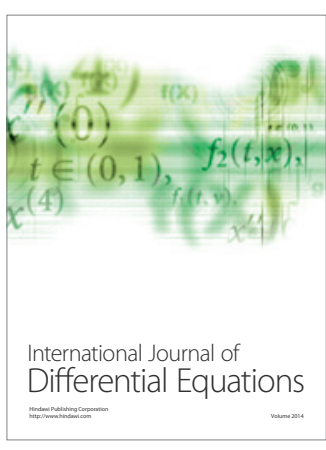
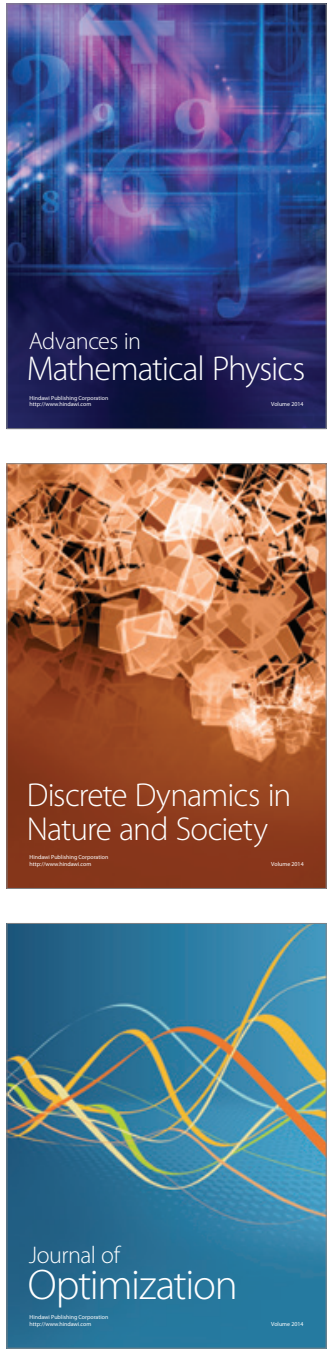